\title{
UM ESTUDO SOBRE O ACOLHIMENTO PRECOCE INSPIRADO NO MÉTODO BICK
}

\author{
Gabriela Golin \\ Sílvia Pereira da Cruz Benetti" \\ Tagma Marina Schneider Donelli
}

\begin{abstract}
RESUMO. Este artigo tem como objetivo apresentar uma adaptação do Método Bick de Observação como técnica de coleta de dados em um estudo realizado em um abrigo localizado no estado do Rio Grande do Sul. Foram observados três bebês com idades entre um e dois anos e seus respectivos cuidadores, o que possibilitou a investigação de três categorias: $\mathrm{O}$ ambiente cuidador; A interação entre criança e cuidadores; e $\mathrm{O}$ impacto emocional no observador. O artigo destaca o valor do Método Bick para fins de pesquisa. Além disso, aborda a possibilidade da prevenção na área da saúde mental na primeira infância por meio desse recurso, contribuindo com a clínica psicológica, especialmente em situações de vulnerabilidade na primeira infância.
\end{abstract}

Palavras-chave: métodos de observação; acolhimento precoce; prevenção.

\section{A STUDY ON EARLY SHELTERING INSPIRED BY BICK METHOD}

\begin{abstract}
The objective of this article is to present an adaptation of Bick's Method of observation as a technique of collecting data for a study made in a sheltering home in the state of RS. Three babies between one and two years old and their caretakers were observed, allowing the investigation of three categories: the caretaking environment, the interaction between the kids and their caretakers and, lastly the emotional impact on the observer. The article stands out the value of Bick's Method to conduct researches. Besides, it shows the possibility of prevention in infant mental health through this resource, contributing to the psychological clinic, especially in situations of infant vulnerability.
\end{abstract}

Key words: Observational methods; early sheltering; prevention.

\section{UN ESTUDIO SOBRE ACOGIMIENTO PRECOZ INSPIRADO EN EL MÉTODO BICK}

RESUMEN. Este artículo tiene como objetivo presentar una adaptación del método de observación Bick como una técnica para recoger datos de un estudio realizado en un abrigo localizado en el estado de RS. Observamos tres bebés de entre uno y dos años y sus cuidadores, lo que posibilitó la investigación de tres categorías: el ambiente cuidador, la interacción entre niños/cuidadores y por fin, el impacto emocional en el observador. El artículo destaca el valor del método Bick para fines de pesquisa además de eso, aborda la posibilidad de la prevención de la salud mental en la primera infancia por medio de ese recurso, contribuyendo con la clínica sicológica, especialmente en situaciones de vulnerabilidad en la primera infancia.

Palabras-clave: Métodos de observación; acogimiento precoz; prevención.

Em 1948, Bowlby convidou Esther Bick para incluir o método de observação de bebês como parte da formação de psicoterapeutas de crianças na clínica Tavistock de Londres (Oliveira-Menegotto, Menezes, Caron \& Lopes, 2006). Assim, a Observação da Relação Mãe-Bebê (ORMB), que é um método psicanalítico de observação desenvolvido por Esther Bick, e por isso chamado também de Método Bick de Observação, foi introduzido como atividade curricular do primeiro ano do curso de formação de terapeutas de crianças do Instituto de Psicanálise de Londres em 1960. No Brasil, esse método vem sendo utilizado

Mestre em Psicologia Clínica pela Universidade do Vale do Rio dos Sinos - UNISINOS, RS. Psicanalista em formação pelo Centro de Estudos Psicanalíticos de Porto Alegre, Brasil.

II Doutora em Estudos da Criança e da Famíla. Universidade de Syracuse, NY, EUA. Professora e pesquisadora do Programa de Pós-graduação em Psicologia Clínica da Universidade do Vale do Rio dos Sinos - UNISINOS, RS, Brasil.

æ Doutora em Psicologia pela Universidade Federal do Rio Grande do Sul, UFRGS, RS. Professora e pesquisadora do Programa de Pós-graduação em Psicologia Clínica da Universidade do Vale do Rio dos Sinos - UNISINOS, RS. Brasil. 
desde 1974, na Sociedade Brasileira de Psicanálise do Rio de Janeiro, e também como atividade de cursos de formação de psicoterapeutas e psicanalistas em instituições gaúchas (Kompinsky, 2000).

Bick (1964/2002) ressaltou que a importância de seu método se deve à compreensão psicodinâmica do desenvolvimento infantil que ele propicia. No caso, a observação detalhada e sensível das fantasias primitivas que envolvem o brincar e a comunicação não verbal possibilita ao psicoterapeuta o entendimento da relação mãe-bebê e sua evolução. Desse modo, conforme Bick (1964/2002), o observador tem a possibilidade de aprender a sentir e a observar e, dessa forma, acessar a compreensão acerca do desenvolvimento precoce, bem como a comunicação pré-verbal diante da interação precoce observada, além de perceber em si próprio, contratransferencialmente, as mobilizações emocionais primitivas a partir do contato com o bebê (Bick, 1964/2002).

O método originalmente proposto por Bick (1964/2002) consiste em visitas semanais ao bebê, do nascimento até seu primeiro aniversário, as quais geralmente ocorrem na residência da família, em dias e horários fixos, e duram uma hora. Já no segundo ano, as visitas acontecem quinzenalmente. A postura de neutralidade do observador envolve sua não interferência ou intervenções conscientes, como, por exemplo, dar conselhos durante a observação. Assim, durante o processo o observador deve manter-se reflexivo, e não ativo. Após a observação, esta deve ser relatada quanto antes possível, tendo-se em vista sua descrição detalhada, que envolve o ambiente, as impressões gerais do observador e os sentimentos gerados nele. Posteriormente, acontece a supervisão semanal com um psicanalista experiente no método. Tal profissional auxilia o observador na contenção e no entendimento das angústias e impressões geradas pela observação, sendo possível compartilhar essa vivência (Bick, 1964/2002).

Além de seu significado clínico, simultaneamente, esse método torna-se um importante recurso para a coleta de dados na realização de pesquisas científicas (Oliveira-Menegotto, Menezes, Caron \& Lopes, 2006), entretanto se constata que, apesar de o Método Bick estar sendo aplicado em diferentes contextos, seu uso em pesquisa ainda foi pouco avaliado e não se encontra difundido, especialmente no meio acadêmico. Para Rosa (1995), o Método Bick não é um método de pesquisa em seu sentido tradicional, todavia o material recolhido nas observações e supervisões costuma revelar pontos passíveis de investigação científica.
Assim, na Inglaterra, Rustin (2001) vem defendendo o uso da observação como método de investigação científica. Ele destaca que o uso do Método Bick em pesquisa requer alto nível de habilidade do observador e um trabalho intenso de coleta de dados, em função das particularidades deste método, além de os locais onde se dão as observações serem difíceis de controlar ou prever. Por outro lado, este método permite um envolvimento e uma investigação mais aprofundada do pesquisador sobre as relações entre mães e bebês, do que seria possível em qualquer situação de laboratório.

Recentemente, esse método vem sendo utilizado em situações especiais, sendo aplicado preventivamente em ambientes diferenciados, além de servir como método de coleta de dados em pesquisa sobre a primeira infância, por exemplo, em creches (Lejderman \& Kompinsky, 2000), em instituições de abrigo (Appell, 1997; Golin \& Benetti, 2010; Siqueira \& Andriatte, 2001) e, com diferentes objetivos, em setores hospitalares (Donelli, 2008; Steibel, 2011; Wirth, 2000). Ainda com relação à pesquisa, o Método Bick tem sido utilizado para investigar a relação mãe-bebê em contextos específicos de vulnerabilidade, como no caso de detenção da mãe no sistema prisional (Candelori \& Dal Dosso, 2007). Pode-se também citar o estudo de Urban (2003) sobre o impacto traumático de experiências próprias do ciclo da vida, além dos estudos de Murray (1997) e Vliegen (2006) sobre o desenvolvimento do bebê no contexto da depressão materna. Destarte, este método vem sendo reconhecido como um importante método de pesquisa (Donelli, 2008; Lopes, Vivian, OliveiraMenegotto, Donelli \& Caron, 2007; OliveiraMenegotto, Menezes, Caron \& Lopes, 2006; OliveiraMenegotto, 2007; Steibel, 2011; Vivian, 2006).

Em vista disso e do fato de que esse estudo refere-se a crianças acolhidas precocemente e aos seus cuidadores, destaca-se o trabalho preventivo realizado por Appell (1997) junto a crianças internadas em uma instituição de abrigo, com a adaptação do Método Bick. Segundo a autora, esta intervenção beneficiou tanto os cuidadores como as próprias crianças observadas. Além disso, para Appell (1997), a instituição que atende essas crianças deve ter sensibilidade para compreender que, em se tratando de uma criança muito pequena, estar em um ambiente físico e humano novo, como é o caso do abrigo, leva-a a sentir-se sozinha e perdida. De fato, pode-se supor que um ambiente desfavorável é assustador até mesmo para os adultos que se ocupam das crianças nesses locais, já que geralmente, em abrigos desorganizados e 
sem suporte emocional aos profissionais, torna-se impossível o desenvolvimento de um cuidado próximo e afetivo com a criança (Appell, 1997). Desse modo, supõe-se que esse método pode ser utilizado como recurso preventivo em situações de vulnerabilidade, além de constituir-se como um importante instrumento de coleta de dados em pesquisas qualitativas.

A partir dessas ideias, o presente trabalho tem como objetivo apresentar uma adaptação do Método Bick de Observação como técnica de coleta de dados em um estudo realizado em um abrigo localizado no Estado do Rio Grande do Sul. Este estudo é derivado de uma dissertação de mestrado cujo objetivo principal foi compreender e analisar as demandas psicológicas de três meninos de idades entre um e dois anos e de seus cuidadores, a partir da sua interação em uma instituição de abrigo. A adaptação do Método Bick possibilitou a investigação de três categorias: "O ambiente cuidador"; "A interação entre a criança o cuidador"; e "Impressões e impacto emocional da pesquisadora". Nesse artigo será apresentada a metodologia utilizada, com ênfase nas particularidades do uso do Método Bick para fins de pesquisa.

\section{MÉTODO}

\section{Participantes}

Este estudo ocorreu em uma instituição de abrigo municipal da região metropolitana de Porto Alegre que, no momento da pesquisa, abrigava 23 crianças com idades entre zero e doze anos. Participaram deste estudo três meninos abrigados, com idades entre um e dois anos, e seus respectivos cuidadores na instituição. Os meninos foram selecionados por conveniência, por preencherem os seguintes critérios de seleção: residir há pelo menos seis meses nesta instituição e ter idade entre um e dois anos.

\section{Procedimentos}

$\mathrm{Na}$ instituição a pesquisadora ${ }^{1}$ observou cada criança em interação com seus cuidadores ao longo de um mês, durante uma hora por semana, em diferentes horários, totalizando cinco observações. A observadora frequentou a instituição durante três meses, e a cada mês uma criança foi o foco das observações. Assim, obteve-se material de observação

1 A observadora foi a autora da dissertação da qual esse estudo se originou. de cinco observações de cada criança, totalizando quinze relatos de observação.

Antes de cada observação a observadora entrava em contato telefônico com a direção, conforme fora solicitado pela instituição nas combinações iniciais. É importante referir que os cuidadores observados aceitaram fazer parte do estudo, e todas as recomendações éticas foram atendidas de acordo com Parecer N. ${ }^{\circ}$ 015/2009 do Comitê de Ética em Pesquisa de uma universidade da região metropolitana de Porto Alegre. Ao dirigir-se ao abrigo, a observadora ia ao encontro das crianças e observava as atividades diárias, que podiam incluir o banho, a troca de fraldas, a hora do brinquedo, a alimentação ou o descanso, possibilitando um amplo conhecimento da rotina diária das crianças no abrigo. Não havia preocupação em prever as situações que seriam observadas.

Como prevê o método originalmente proposto por Bick (1964/2002), as observações foram relatadas em momento posterior, tendo em vista que esse método requer a atenção flutuante do pesquisador no momento da observação (Bick, 1964/2002; Lopes et al., 2007). Após o relato, a pesquisadora contou com a supervisão individual de uma psicanalista especialista no método.

Nesse sentido, apesar da necessidade de adaptação do método, tendo-se em vista o tempo previsto para a realização de uma pesquisa de mestrado, seus princípios básicos foram seguidos: a observação, o relato das observações e a supervisão dos casos relatados (Bick, 1964/2002). Concluídas as observações, todos os relatos desses momentos foram novamente lidos, a fim de construir uma síntese de cada um dos casos (três ao todo). Após essa releitura, emergiram três categorias de análise: "O ambiente cuidador" (o dia a dia institucional, ou seja, o ambiente e a disponibilidade dos cuidadores ante as necessidades dos bebês, a partir do seu atendimento); A interação criança-cuidadores" (envolvimento recíproco entre as crianças observadas e seus cuidadores); e "Impressões e impacto emocional na pesquisadora" (impacto emocional vivenciado pela pesquisadora durante as observações). Assim, a partir do material coletado e do que se repetiu ao longo dos relatos, foi possível um breve entendimento de cada caso, o que facilitou a análise das demandas psicológicas das crianças e dos próprios cuidadores. Nesse sentido, valorizaram-se as comunicações observadas em nível verbal e também não verbal, já que o método Bick enfatiza a importância do entendimento das comunicações primitivas a partir do impacto emocional vivenciado pelo observador (Bick, 1964/2002). 


\section{RESULTADOS E DISCUSSÃO}

$\mathrm{Na}$ categoria "Ambiente cuidador", torna-se importante destacar que a casa onde fica esta instituição de acolhimento é espaçosa, limpa e clara. As crianças dispõem de vários brinquedos, tendo um espaço amplo para explorar, tanto em sua parte interna como na parte externa. A equipe técnica que acompanha as crianças é bastante ampla (diretora, psicóloga, assistente social, pedagogo), e os profissionais (cuidadores) mostram preocupar-se com o tratamento às crianças. Na faixa etária das crianças observadas, é relevante referir que havia nove crianças entre um e dois anos de idade na instituição, incluindo as três crianças que fizeram parte do estudo. Na maior parte do tempo, elas eram cuidadas por dois profissionais em cada turno. Desse modo, percebeu-se que a instituição faz um real esforço para que as crianças tenham cuidadores constantes nos três turnos e se interessa pelo bem-estar dos pequenos.

Esse dado vai em direção do resultado obtido por David e Appell (1964), que realizaram o seu estudo em uma instituição reconhecida pela qualidade da sua estrutura física. Apesar disso, evidenciaram que a carência afetiva das crianças institucionalizadas é algo muito complexo, que vai além da preocupação dos profissionais, da organização e do visual da instituição.

Assim, apesar de haver a preocupação e o desejo de manter certa rotina no cotidiano das crianças, percebeu-se, de maneira geral, que o ambiente não possibilitava uma rotina constante. Observou-se que a organização diária dependia da dupla de cuidadores responsáveis pelas crianças e que estes se alternavam conforme a demanda da institução.

De modo geral, pela manhã, as crianças ficavam em seu quarto, e após a mamadeira poderiam ficar no berço ou no chão. Elas também recebiam cuidados com a higiene, e, em seguida brincavam e assistiam desenhos. Nesse turno, as cuidadoras principais dividiam os bebês: os menores (que ainda não caminhavam) ficavam no quarto, enquanto os maiores, mais independentes, ficavam com a outra cuidadora no quarto dos brinquedos. $\mathrm{O}$ almoço era servido no meio da manhã, respeitando-se esta divisão. Depois de um tempo, as crianças descansavam novamente em seus berços. À tarde, durante as observações, as crianças acordavam, e à medida que isto acontecia, recebiam a mamadeira com leite em seus berços. Normalmente, neste turno, elas permaneciam juntas em seu quarto ou no quarto de brinquedos. A dupla de cuidadores organizava-se e trabalhava no mesmo ambiente. As crianças, depois que tomavam o leite, recebiam cuidados com a sua higiene, como troca de fraldas e banho. Todas eram atendidas e depois colocadas livremente no chão do quarto, onde brincavam, faziam o lanche da tarde e assistiam desenhos.

Além disso, notou-se que as crianças recebiam mais atenção individualizada durante o banho, mas este, geralmente, também acontecia de forma rápida, devido ao número dos bebês que aguardavam para ser atendidos. Assim, os cuidados eram dispensados de maneira apressada, de acordo com a rotina institucional.

$\mathrm{Na}$ categoria "Interação criança-cuidadores", notou-se que a rotina de cuidados variava segundo os cuidadores responsáveis, o turno de trabalho e as intercorrências institucionais, como faltas, atrasos e atestados dos profissionais. Assim, percebeu-se que não havia uma constância no padrão dos cuidados dispensados, a partir do qual os cuidadores pudessem interagir de forma previsível com as crianças no dia a dia da instituição. A rotina apressada não possibilitava cuidados individualizados às comunicações e demandas infantis, como foi possível inferir das observações:

(...) estava em seu berço, estava deitado, brincando com as mãos no ar, enquanto chupava sua chupeta... Então, ele se virou e segurou nas grades do berço, se ergueu bem devagar, pareceu fazer força nesse movimento e, com certo esforço, ele ficou de joelhos. Segurou-se na guarda da cama com uma mão e com a outra, que estava livre, ele pegou o bico que estava na boca, jogando-o para o chão! Fez isso olhando para a cuidadora, que devolveu o bico sorrindo. Então, ele pegou o bico também sorridente. Em seguida, olhando para esta cuidadora, ele jogou o bico novamente no chão! (A cuidadora) the disse: 'Agora o bico é meu! É meu!'. Ela guardou o bico no bolso do seu avental e Miguel $^{2}$ ficou olhando para ela, quieto. Depois, ele se deitou, virou para o lado quietinho pareceu adormecer novamente (relato $\mathrm{n}^{\circ}{ }^{3}$ ).

Nesse sentido, conforme o estudo de Appell (1997), o dia a dia no abrigo acaba por impedir contatos mais sensíveis e de qualidade entre crianças e cuidadores. Cabe ressaltar que existem particularidades, tanto das crianças como dos próprios cuidadores, que interferem na interação. Observou-se, por exemplo, que os cuidadores realizavam os cuidados apressadamente, talvez devido à mobilização

\footnotetext{
2 Todos os nomes utilizados neste trabalho são fictícios.
} 
emocional que o desamparo e a carência afetiva e emocional das crianças despertavam neles (David \& Appell, 1964).

Por último, na categoria "Impressões e impacto emocional da pesquisadora", foram descritos os sentimentos e o impacto emocional causados na pesquisadora durante as observações. Inicialmente a pesquisadora sentiu-se perdida durante as primeiras observações. Eram várias as pessoas que circularam e que trabalhavam na instituição (no momento do estudo), sendo difícil entender quem era quem, ao menos num primeiro momento. Além disso, durante as observações de Maurício, que foi o primeiro bebê observado, a pesquisadora sentiu-se desconfortável, pois tentava observá-lo e, ao mesmo tempo, tinha a impressão de que seria difícil olhar somente para ele. Eram muitos os bebês e, na maior parte das vezes as crianças estavam chorando, querendo e precisando ser atendidas.

Durante a supervisão, refletiu-se acerca da identificação da pesquisadora com as crianças: esta sentia-se perdida e desamparada como as crianças se sentem ao chegar ao local, sem saber o que fazer ou como fazer o que pretendia. A realidade institucional impõe-se e as crianças precisam se adaptar ao ambiente, assim como ocorreu com a observadora no início do trabalho.

Quando a pesquisadora iniciou as observações de Maurício, o primeiro bebê observado, era comum ela ter dificuldades em identificá-lo e diferenciá-lo das outras crianças. Somente aos poucos e com esforço é que ela conseguia identificá-lo. No período do estudo, havia nove bebês, todos juntos, ocupando a mesma sala. Somando-se a isso, eles se pareciam muito uns com os outros: cabelos escuros, pele morena, idades aproximadas e, em sua maioria, meninos - mais precisamente, oito meninos e uma menina, a Paula. Pôde-se refletir também sobre a dificuldade da instituição em lidar com tantos bebês, bem como de se organizar ao deparar-se com tamanha demanda, o que "explica" a pressa nos cuidados diários. Neste sentido, além do entendimento anterior, torna-se relevante citar os resultados de David e Appel (1964), que apontam em seu estudo o fato de que os cuidadores se defendem emocionalmente do contato mais próximo dos bebês, provavelmente pelo forte impacto emocional que esta interação lhes acarreta. Assim, entende-se que muitas vezes esse distanciamento afetivo acontece a partir de uma rotina movimentada, que tende a impedir interações diferenciadas entre o cuidador e a criança. Pode-se supor que é uma tentativa dos cuidadores de proteger-se ou afastar-se desse sentimento ou sensação de carência extrema, vivenciados por estas crianças.

Além disso, as tosses contínuas, as respirações trancadas e roucas incomodavam e angustiavam a pesquisadora. Por exemplo, parecia-lhe que Maurício estava permanentemente doente em função da sua voz, sempre rouca; ou a doença aparecia nos relatos por meio de um bebê que respirava com dificuldades, que choramingava baixinho e emitia um choro fraco e contínuo.

Inevitavelmente, logo após as observações, a pesquisadora ficava pensando nas crianças. Isso acontecia de forma intensa, tanto que teve dificuldades de ir embora ao final de algumas observações, ao mesmo tempo em que se sentia aliviada por poder sair do ambiente.

Outro fato que também mobilizou a pesquisadora foi o tempo em que as crianças ficavam nos berços, assistindo televisão ou brincando com seu próprio corpo, até que todos fossem atendidos. Por exemplo, isso ficou evidente na última observação de Maurício, no momento em que ele ficou esperando por uma hora em seu berço, para ser atendido:

\begin{abstract}
Maurício se espreguiçou em sua cama, fazendo um som de carrinho 'brumm!'. Depois começou a dar gritinhos 'Ah!'. Eram vários gritinhos isolados. Ele fez tentativas de colocar a meia no pé direito e esta caía novamente ao seu lado. Ele olhava para seu pé. Estava deitado, então, começou a juntar um pé com o outro no ar: 'Dá! Dada!'. Em alguns momentos choramingava olhando na direção dos cuidadores, depois, acabava se distraindo novamente com a sua meia ou com a televisão. Ele ficou durante uma hora no berço, se distraindo com o seu corpo, com suas roupas, com a televisão... (Relato $\left.\mathrm{n}^{\circ} 4\right)$.
\end{abstract}

Já com relação ao Cristofer, o terceiro bebê observado, a pesquisadora sentiu-se preocupada com ele, além de mais cansada em todas as suas observações. Em supervisão, refletiu-se que ele é um bebê que não obedece e não ouve os cuidadores, causando, desse modo, certo cansaço, e um desinvestimento afetivo por parte deles. Além disso, supõe-se que a sua expressão, sempre séria e triste, também não favoreça uma aproximação por parte dos cuidadores. Supõe-se que essa distância afetiva aconteça também por temerem chegar perto de seu desamparo, evidenciado por sua expressão.

Com relação aos cuidadores, certo dia, indo a pesquisadora até o quarto dos bebês, uma das cuidadoras cumprimentou-a dizendo: "Vou trocar o turno, agora estarei aqui pela manhã, se quiser vir 
também pela manhã eu te agradeço!" (relato $\mathrm{n}^{\circ} 3$ Maurício). Tal comentário chamou a atenção da observadora para o fato de que as próprias cuidadoras estivessem criando expectativas de acolhimento psicológico para si mesmas. Assim, refletiu-se em supervisão acerca do desamparo das próprias cuidadoras, que também pediam atenção, apesar de terem acompanhamento técnico constante (reuniões quinzenais de uma hora), principalmente da diretora da instituição, de uma psicóloga e de uma assistente social, que acompanhavam os casos e situações específicas de cada cuidadora.

Além disso, a pesquisadora sentiu-se identificada com os cuidadores, principalmente quando precisou "trocar de criança" para realizar o estudo, mais especificamente, nas observações. Não poderia ficar somente com a primeira criança, tinha que dar conta dos três bebês do estudo, já que teria três meses para realizar a coleta de dados. Essa condição causou-lhe culpa, impotência e mal-estar, além de ela sentir-se também "apressada".

Constatou-se, a partir dos dados da pesquisa, a necessidade de maior constância nos cuidados como uma das demandas psicológicas das três crianças observadas, levando a um reconhecimento de sua individualidade. Esse dado vai ao encontro dos achados de estudos clássicos e contemporâneos acerca do acolhimento precoce (Bowlby, 1976/2006; David \& Appell, 1964; Nogueira \& Costa, 2005; Parreira \& Justo, 2005; Rygaard, 2008; Siqueira \& Andriatte, 2001; Smyke, Dumitrescu \& Zeanah, 2002; Vectore \& Carvalho, 2008; Winnicott, 1984/2002), que enfatizam, na situação de ruptura com a família biológica, a necessidade de um contato receptivo e estável dessas crianças com um cuidador substituto, que possibilite o desenvolvimento do apego discriminado (Gauthier, Fortin \& Jéliu, 2004; Rygaard, 2008; Wendland \& Gaugue-Finot, 2008), de forma a amenizar os prejuízos causados pela privação materna e os traumas dela decorrentes (Rygaard, 2008; Smyke et al., 2002).

Outro dado importante deste estudo foi a busca ativa das três crianças observadas pelos seus cuidadores. Quando não atendidas e reconhecidas em suas demandas, elas mostraram-se angustiadas, assustadas e irritadas, sendo que, em alguns momentos, pareciam até mesmo desistir desse retorno. Tal situação converge com os resultados do estudo de David e Appell (1964), os quais perceberam que, quando não eram correspondidas, sendo pouco percebidas em suas manifestações espontâneas - como sorrisos e balbucios - as crianças deixavam de fazer essas tentativas de aproximação pela ausência de retorno ou resposta dos cuidadores.

Diante disso, Appell (1997) reforçou que um ambiente fisicamente organizado poderá facilitar o trabalho de cuidado com as crianças acolhidas. Por outro lado, também salientou em seu estudo que a maior necessidade nesse contexto é o amparo constante aos profissionais que se ocupam das crianças, para que eles não fiquem simplesmente se defendendo dos sentimentos acionados nas interações e possam trabalhar mais seguramente.

O paradoxo existente entre a qualidade da organização física da instituição e o ambiente emocional oferecido às crianças também foi percebido neste estudo. Segundo os cuidadores, o ambiente como um todo é adequado e fisicamente organizado, mas não há um padrão de cuidados. Somando-se a isso, os cuidadores contam com acompanhamento técnico para melhor atender as crianças; entretanto, apesar desse importante cuidado com os cuidadores e com as crianças, notou-se a dificuldade dos cuidadores em lidar com as crianças no dia a dia, talvez pela falta de constância do trabalho e de um treinamento mais específico. Além disso, as demandas das crianças e os próprios sentimentos dos cuidadores reforçam a sua necessidade de maior amparo psicológico e de supervisão mais individualizada, de forma a favorecer o seu trabalho, considerando-se a mobilização emocional que esta tarefa diária envolve. Assim, poderá ser mais bem trabalhado e entendido o sentimento acionado nos cuidadores a partir do cuidado e da interação estabelecida com cada criança.

Neste sentido, a observação pelo Método Bick proporcionou a percepção de distintos padrões de interação estabelecidos entre as crianças e os cuidadores. Pôde-se investigar e compreender as características subjetivas e comportamentais, tanto dos bebês, quanto dos próprios cuidadores, além de formas e tendências de interação entre eles em seu próprio contexto. Assim, pode-se pensar inclusive preventivamente, tendo-se maior clareza e entendimento dos afetos mobilizados durante as interações com as crianças. A partir desse entendimento e de um trabalho mais individualizado, é possível esses profissionais estabelecerem um holding com elas.

\section{CONSIDERAÇÕES FINAIS}

O Método Bick é frequentemente comparado com o próprio método de observação em psicanálise. Conforme Rosa (1995), há pontos em comum entre ambos, como a premissa de observar as mesmas coisas 
repetidas vezes, até que elas mesmas comecem a falar, fazendo emergir padrões de comportamento passíveis de entendimento. Desse modo, outra semelhança seria o fato de ambos os métodos trabalharem com a falta de acesso direto a produções da mente humana que interessam, tais como fantasias, emoções, ansiedade, mecanismos mentais e representações. Mesmo quando há palavras envolvidas, elas nem sempre revelam, em seu conteúdo imediato, o que se quer saber, pois as palavras são, elas próprias, transformações à espera de reconhecimento no domínio do relacionamento humano.

Destarte, tanto no Método Bick como na observação em psicanálise, a questão da comunicação não simbólica se faz presente, e pode ser amparada no conceito de identificação projetiva (Bion, 1962/1991; Klein, 1969). Rustin (2001) diferencia o Método Bick do método de pesquisa empírica tradicionalmente utilizado pela psicologia do desenvolvimento infantil. Para o autor, este último é, em geral, de tipo analítico, isto é, procura analisar formas complexas de comportamento e de interação identificando e estudando separadamente seus elementos, enquanto no Método Bick,procura-se identificar uma coerência no todo, além de padrões recorrentes de comportamento envolvidos no relacionamento familiar.

De acordo com Rustin (2001), o Método Bick possui traços em comum com alguns métodos das ciências sociais, especialmente a sociologia e a antropologia, pois tanto aquele quanto estes últimos requerem observadores capazes de não substituir de forma antecipada e precipitada a observação em si por teorias, conceitos e expectativas. Apesar disso, exigese do observador que ele tenha em mente uma série de concepções e expectativas latentes, com as quais possa dar coerência e forma às suas experiências e, ao mesmo tempo, manter sua mente aberta e receptiva para situações e eventos particulares a que venha a estar exposto.

Nessa direção, denota-se que no presente estudo, cujo objetivo foi apresentar uma adaptação do Método Bick de Observação como técnica de coleta de dados, não houve um foco preestabelecido, especialmente durante as observações. Somente após as observações é que as categorias foram elaboradas, justamente para que se pudesse responder à questão do estudo maior no qual esse artigo foi embasado, ou seja, quais são as demandas e necessidades de bebês institucionalizados precocemente e de seus cuidadores. Assim, a partir das categorias eleitas: "O ambiente cuidador"; "Interação criança-cuidadores" e "Impressões e impacto emocional da pesquisadora", foi possível a análise dos dados coletados tendo-se como foco o objetivo do estudo. Desse modo, com este método foi possível investigar as crianças no local onde elas vivem e são acolhidas respeitando-se sua rotina e, ao mesmo tempo, entendê-las e às suas demandas por meio da observação do ambiente global.

Deve-se considerar ainda que o Método Bick é um método psicanalítico de observação. Diferentemente dos métodos experimentais, que visam pôr em evidência determinado fenômeno a partir de uma hipótese teórica que o embasa, o método psicanalítico leva em conta situações geralmente negligenciadas por outros métodos observacionais, tais como os estados psíquicos internos tanto do sujeito observado como do próprio observador. Nesse sentido, o enquadre é fundamental para o fenômeno que se quer observar. O limite espaçotemporal (que permite definir o espaço concreto da observação), o limite contratual (o que está sendo proposto) e os limites psíquicos (que dependem do que o observador percebe por seus sentidos, por sua emoção, por sua atividade imaginária e por sua capacidade de pensar) são os limites do enquadre, e são justamente eles que constituem o objeto da atenção do observador. É através de um enquadre cuidadosamente definido que o inesperado vem à tona, pois é sua função criar as condições para que o inesperado apareça, para que se crie um espaço psíquico livre de situações anteriores e para que não seja observado apenas aquilo que a teoria prevê (Houzel, 1997).

Esse conceito de teoria do enquadre proposto por Houzel (1997) visa dar conta de um problema que tem se mostrado um dos pontos de críticas ao método proposto por Bick (1964). A epistemologia moderna evidenciou que não há possibilidade de observar, por meio de nenhum método, sem uma teoria que possa recolher os dados das observações, articulá-los e lhes dar sentido.

Assim, no presente estudo, que foi inspirado no Método Bick, foi possível a investigação detalhada e a análise do contexto do abrigo, bem como das demandas das crianças acolhidas e de seus cuidadores, a partir da observação da sua interação com os cuidadores neste ambiente, diante da sua realidade diária. Este método tem sido aplicado a inúmeros contextos, como já exposto anteriormente, tais como unidades de tratamento intensivo neonatal, enfermarias de cardiologia pediátrica, ultrassonografias gestacionais, berçários, creches, hospitais gerais e prisões femininas (Candelori \& Dal Dosso, 2007).

Além disso, a coleta de dados seguiu os três tempos propostos por Bick (1964): observação, relato e supervisão. Assim, os limites que configuraram o 
espaço concreto da observação, definiram o contrato de trabalho e permitiram estabelecer um enquadre psíquico estiveram presentes na coleta de dados para esse trabalho.

Em suma, constata-se que este método pode ser uma excelente ferramenta clínica, capaz de auxiliar no trabalho preventivo em diversas situações, destacandose como exemplo disso o trabalho de Appell (1997), referido anteriormente, que o utilizou para intervir preventivamente em uma instituição de acolhimento, por meio de um trabalho de reflexão e sensibilização com os cuidadores das crianças. Além disso, este é também uma importante ferramenta para a pesquisa em psicanálise, sendo extremamente eficaz em pesquisas qualitativas, especialmente naquelas que envolvem fenômenos próprios do início da vida; entretanto é importante que este recurso seja respeitado em seus princípios e que seja utilizado de forma ética, por profissionais que tenham treinamento específico.

\section{REFERÊNCIAS}

Appell, G. (1997). Que tipo de observação usar para acompanhar uma criança pequena em coletividade. (F. F. Settineri, Trad.). In M. B. Lacroix \& M. Monmayrant (Ed.), Os laços do encantamento: A observação de bebês segundo Esther Bick e suas aplicações (pp. 79-85). Porto Alegre: Artes Médicas.

Bick, E. (2002). Notes on infant observation in psycho-analytic training. In A. Briggs (Ed.), Surviving Space: papers on infant observation (pp. 37-54). Londres: Karnac. (Original publicado em 1964).

Bion, W. R. (1991). O aprender com a experiência (P. D. Corrêa, Trans.). Rio de Janeiro, Brasil: Imago. (Original publicado em 1962).

Bowlby, J. (2006). Cuidados maternos e saúde mental (5a ed.). São Paulo: Martins Fontes. (Original publicado em 1976).

Candelori, C., \& Dal Dosso, M. (2007). An experience of infant observation in a prision. Infant Observation, 10(1), 59-69.

David, M., \& Appell, G. (1964). Etude des facteurs de carence affective dans une pouponnière. Psychiatrie de I'enfant, 4, 401442.

Donelli, T. (2008). Descortinando a vivência emocional de mulheres em um centro obstétrico: Uma investigação sobre o parto através do Método Bick. Projeto de Tese de Doutorado Não-Publicada, Programa de Pós-Graduação em Psicologia, Universidade Federal do Rio Grande do Sul, Porto Alegre.

Gauthier, Y., Fortin, G., \& Jéliu, G. (2004). Applications cliniques de la théorie de l'attachement puor les enfants em famille d'accueil: Importance de la continuité. Médicine e Hygiène Devenir, 16, 109-139.

Golin, G., \& Benetti, S. (2010). O abrigamento precoce: vínculos iniciais e desenvolvimento infantil. In M. H. P. Franco (Ed.), Formação e Rompimento de Vínculos: o dilema da atualidade (pp. 169-190). São Paulo: Summus Editorial.
Houzel, D. (1997). Observação de bebês e psicanálise, ponto de vista epistemológico (F.F. Settineri, Trans.). In M. B. Lacroix \& Monmayrant (Eds.), Os laços do encantamento: a observação de bebês segundo Esther Bick e suas aplicações (pp.87-94). Porto Alegre: Artes Médicas.

Klein, M. (1969). Sobre a identificação. In M. Klein, P. Heimann \& R. E. Money-Kyrle (Eds.) Temas de Psicanálise Aplicada. Rio de Janeiro, Brasil: Zahar Editores.

Lejderman, A. \& Kompinsky, E. (2000). Caráter preventivo da aplicação da observação da relação mãe-bebê em uma creche. In N. A. Caron (Ed.), A relação pais-bebê: da observação à clínica (pp. 268-288). São Paulo: Casa do Psicólogo.

Lopes, R., Vivian, A., Oliveira-Menegotto, L., Donelli, T., \& Caron, N. (2007). A observação da relação mãe bebê através do método Bick. In C. A. Piccinini \& M. L. Seidi de Moura (Eds.), Observando a Interação Pais-Bebê-Criança (pp.73-102). São Paulo: Casa do Psicólogo.

Murray, L. (1997). The early mother-infant relationship and child development: a research perspective. Infant Observation, 1(1), 8092.

Nogueira, P., \& Costa, L. F. (2005). Mãe social: Profissão? Função materna? Estilos da Clínica, 10(9), 162-181.

Oliveira-Menegotto, L. M. de. (2007). O desamparo materno diante de seu bebê com Síndrome de Down: aplicação do Método Bick de observação da relação mãe-bebê. Tese de Doutorado NãoPublicada, Programa de Pós-Graduação em Psicologia, Universidade Federal do Rio Grande do Sul, Porto Alegre.

Oliveira-Menegotto, L., Menezes, C., Caron, N., \& Lopes, R. (2006). $\mathrm{O}$ método Bick de observação de bebês como método de pesquisa. Psicologia Clínica, 18(2), 1-11.

Parreira, S. M. C. P., \& Justo, J. S. (2005). A criança abrigada: considerações acerca do sentido da filiação. Revista Psicologia em Estudo, 10, 175-180.

Rosa, J. C. (1995). Reflexões sobre o método da observação mãebebê. Revista Brasileira de Psicanálise, 29(2), 299-305.

Rustin, M. J. (2001). Reason and unreason: Psychoanalysis, science and politics. London: Continuum Books.

Rygaard, N. P. (2008). El nino abandonado: Guia para el tratamiento de los transtornos del apego. Barcelona: Gedisa.

Siqueira, L. A., \& Andriatte, A. M. (2001). Um estudo observacional sobre o vínculo afetivo de bebês abrigados em instituições. Boletim de Iniciação Científica em Psicologia, 2, 08-25.

Smyke, A. T., Dumitrescu, A., \& Zeanah, C. H. (2002). Attachment disturbances in young children I: The continuum of caretaking causality. Journal of the American Academy of Child and Adolescent Psychiatry, 41, 972-982.

Steibel, D. (2011). As vivências primitivas de um bebê nascido extremamente prematuro no ambiente da UTI neonatal: uma aplicação do Método Bick de observação. Dissertação de Mestrado Não-Publicada, Programa de Pós-Graduação em Psicologia, Universidade Federal do Rio Grande do Sul, Porto Alegre.

Urban, E. (2003). Developmental aspects of trauma and traumatic aspects of development. Journal of Analytical Psychology, 48, 171-190.

Vectore, C., \& Carvalho, C. (2008). Um olhar sobre o abrigamento: a importância dos vínculos em contexto de abrigo. Psicologia Escolar e Educacional, 12(2), 01-14. 
Vivian, A. G. (2006). O desenvolvimento emocional de um bebê em uma família numerosa: Uma aplicação do método Bick de observação. Dissertação de Mestrado Não-Publicada, Programa de Pós Graduação em Psicologia, Universidade Federal do Rio Grande do Sul, Porto Alegre.

Vliegen, N. (2006). 'She doesn't want to look at me'. Mother - infant observation as a bridge between clinical practice and research. Infant Observation, 9(3), 261-268.

Wendland, J., \& Gaugue-Finot, J. (2008). Le développement du sentiment d'affiliation des enfants placés en famille d'accueil pendant ou après leur petite enfance. Médicine et Hygiène, 20, 319-345.

Winnicott, D. (2002). Privação e Delinquencia. (A. Cabral, Trad.). São Paulo: Martins Fontes. (Original publicado em 1984).
Wirth, A. (2000). Aplicação do método de observação de bebês em uma UTI neonatal. In N. A. Caron (Ed.), A relação pais-bebê: da observação à clínica (pp. 207-232). São Paulo: Casa do Psicólogo.
Endereço para correspondência:
Gabriela Golin. Programa de Pós-Graduação em Psicologia, Av. Unisinos, 950, Bairro Cristo Rei, CEP 93022-000, São Leopoldo-RS.E-mail: silvia.benetti@pq.cnpq.br. 